\title{
The Roles of YouTube and WhatsApp in Dementia Education for the Older Chinese American Population: Longitudinal Analysis
}

\author{
Sara Shu ${ }^{1,2}$, BS; Benjamin K P Woo ${ }^{1}$, MD \\ ${ }^{1}$ University of California, Los Angeles, Sylmar, CA, United States \\ ${ }^{2}$ College of Osteopathic Medicine of the Pacific, Western University of Health Sciences, Pomona, CA, United States
}

\section{Corresponding Author:}

Sara Shu, BS

University of California, Los Angeles

14445 Olive View Drive

Sylmar, CA, 91342

United States

Phone: 17472103830

Email: $\underline{\text { sarashu@gmail.com }}$

\section{Abstract}

Background: Dementia remains a stigmatized topic in the Chinese community.

Objective: This study aims to analyze and compare the usage of dementia educational YouTube videos and the modalities of video sharing over a 6-year period.

Methods: Dementia educational videos were uploaded to YouTube. Data was collected over a 6-year period. Results from the first 3 years were compared to those from the second 3 years using descriptive statistics and chi-square analysis.

Results: Over 6 years, the dementia educational videos generated a total watch time of 269,388 minutes, 37,690 views, and an average view duration of 7.1 minutes. Comparing the first and second 3-year periods of video performance data, there was a longer watch time (59,262 vs 210,126 minutes), more total views (9387 vs 28,303 views), and a longer average view duration (6.3 vs 7.4 minutes). Furthermore, WhatsApp has become a leading external traffic source and top sharing service, accounting for $43.5 \%$ (929/2137) and 67.0\% (677/1011), respectively.

Conclusions: Over 6 years, YouTube has become an increasingly popular tool to deliver culturally sensitive dementia education to Chinese Americans. WhatsApp continues to be the preferred method of sharing dementia education and has become a top external traffic source to dementia educational videos. Taken together, these social media platforms are promising means of reducing the disparity in dementia knowledge in linguistically and culturally isolated populations.

(JMIR Aging 2020;3(1):e18179) doi: 10.2196/18179

\section{KEYWORDS}

dementia; mental health; social media; geriatrics; health promotion; health education

\section{Introduction}

Social media has become a powerful means for health communication to and among the general public, patients, and health professionals alike [1]. Since its debut in 2005, YouTube has become one of the world's most popular social media platforms and a major contributor to the accessibility and dissemination of health information around the world [2].

Dementia is a progressive and irreversible neurocognitive disorder that severely impairs an individual's ability to independently function, which inadvertently causes tremendous burden to family members and caregivers [3]. Although no

current therapy can reverse the steady cognitive decline, early and accurate diagnosis has proven efficacious in prolonging quality of life and allowing both the patient and family time to adjust to changes [4]. Consequently, it is necessary to increase public awareness of this diagnosis to promote early intervention amongst all ethnic communities.

Dementia remains a stigmatized subject in the Chinese community, and the scant availability of language-appropriate and culturally sensitive education is a barrier to encouraging those affected from seeking help [5-7]. Work has been done to promote dementia awareness in the Chinese-American community via radio shows, television episodes, and short films [8-10]. Previous studies have demonstrated that YouTube has 
the potential to successfully deliver dementia education to the older Chinese population [11-15]. In addition, studies have also identified WhatsApp as a promising means for disseminating such dementia education [16].

In this study, we aim to analyze how the Chinese-speaking public search for and share dementia educational videos and evaluate the usage of various social media platforms over time. To our knowledge, this is the first study to present such longitudinal data.

\section{Methods}

\section{YouTube}

A board-certified psychiatrist delivered 2 educational talk shows in Cantonese on a North American Chinese television station in Los Angeles, California. The content of the videos included discussing the background, management, and prevention of dementia. Real-time recordings were subsequently uploaded to YouTube as two 25-minute videos.

\section{Sample}

The sample of this study included YouTube video viewers over a 6-year period (January 2014-December 2019).

\section{Statistical Analysis}

Data was extrapolated from YouTube Analytics. A number of parameters were recorded including number of views, watch time, average view duration, devices used to view, traffic sources, and modes and means of sharing via various social media platforms. Years 1 to 3 (January 2014-December 2016) and years 4 to 6 (January 2017-December 2019) were dichotomized. Descriptive statistics and chi-square tests were used to compare data collected between the first and second 3 -year intervals.

This study used anonymous data collected by YouTube exclusively. A waiver for Institutional Review Board exemption was obtained through the University of California, Los Angeles-Human Subjects Protection Committee.

\section{Results}

In 6 years, the two videos of interest accrued a total watch time of 269,388 minutes and 37,690 views, resulting in an average view duration of 7.1 minutes. Broken down into two 3-year intervals, the data are as follows. The latter 3 years had increased performance in all parameters: longer total watch time increased number of views, and longer average view duration.

The average view duration on mobile devices (eg, mobile phone, tablet) between the former and latter 3-year intervals increased $17.0 \%$ from 6.9 minutes to 8.1 minutes. On the other hand, average view duration on computers increased $6.9 \%$ from 5.8 minutes to 6.2 minutes. There is a significant increase in mobile device usage compared to computer usage from the first 3-year window to the second 3 year window $(66.6 \%$ vs $78.0 \%$, $\chi_{1}^{2}=488.05, P<.001$ ) (Table 1).

Table 1. Devices used for viewing.

\begin{tabular}{lllllll}
\hline Devices & \multicolumn{2}{l}{ Jan 2014-Dec 2016 } & \multicolumn{2}{c}{ Jan 2017-Dec 2019 } \\
& Minutes & Views & AVD $^{\mathrm{a}}(\mathrm{min})$ & Minutes & Views & AVD (min) \\
\hline Computer & 18,292 & 3132 & 5.8 & 38,352 & 6226 & 6.2 \\
Mobile device & 40,970 & 6255 & 6.9 & 171,774 & 22,077 & 8.1 \\
Total & 59,262 & 9387 & 6.3 & 210,126 & 28,303 & 7.4 \\
\hline
\end{tabular}

${ }^{\mathrm{a} A V D}$ : average view duration.

Comparing traffic sources, externally sourced views increased from $6.6 \%$ (621/9387 views) to $7.5 \%$ (2137/28,303 views) between the two 3-year periods. Of external sources, the top platforms remained Google search and WhatsApp, followed by Facebook. Over 6 years, traffic generated from Google search decreased from $1.5 \%$ to $1.1 \%$ of total views (138/9387 vs $302 / 28,303)$, Facebook generated traffic source decreased from $0.3 \%$ to $0.2 \%$ of total views $(30 / 9387$ vs $54 / 28,303)$, and WhatsApp traffic source increased from $0.6 \%$ to $3.3 \%$ of total views $(59 / 9387$ vs 929/28,303). Between the former and latter 3-year periods, WhatsApp traffic source surpassed that of
Google search with statistical significance $(0.6 \%$ vs $3.3 \%$, $\chi_{3}^{2}=225.78, P<.001$ ) (Table 2).

Table 3 shows the comparison between different sharing services. In comparing the two periods, there was a significant increase in usage of WhatsApp for sharing and movement away from sharing via email ( $66.4 \%$ vs $\left.66.9 \%, \chi^{2}{ }_{4}=27.82, P<.001\right)$.

Taken together, although there is a significant increase in traffic generated from WhatsApp between the 2 periods, WhatsApp remains more frequently used for sharing services than viewing capabilities $\left(66.9 \%\right.$ vs $\left.3.3 \%, \chi_{1}^{2}=33.3, P<.001\right)$. 
Table 2. Traffic sources.

\begin{tabular}{|c|c|c|c|c|c|c|}
\hline \multirow[t]{2}{*}{ Traffic sources } & \multicolumn{3}{|c|}{ Jan 2014-Dec 2016} & \multicolumn{3}{|c|}{ Jan 2017-Dec 2019} \\
\hline & Minutes & Views & $\operatorname{AVD}^{\mathrm{a}}(\min )$ & Minutes & Views & AVD (min) \\
\hline \multicolumn{7}{|l|}{ Top 4 traffic sources } \\
\hline Suggested videos & 39,432 & 5288 & 6.6 & 128,448 & 15,942 & 8.1 \\
\hline YouTube search & 9468 & 1696 & 5.6 & 8130 & 1606 & 5.1 \\
\hline Browse features & 6642 & 954 & 6.9 & 46,680 & 6345 & 7.4 \\
\hline External & 3228 & 621 & 5.2 & 11,400 & 2137 & 5.3 \\
\hline \multicolumn{7}{|c|}{ Top 4 external traffic sources } \\
\hline Google search & 600 & 138 & 4.3 & 1404 & 302 & 4.6 \\
\hline WhatsApp & 336 & 59 & 5.7 & 4656 & 929 & 5.0 \\
\hline Facebook & 222 & 30 & 7.4 & 378 & 54 & 7.0 \\
\hline Apple app & 294 & 31 & 9.5 & 270 & 30 & 9.0 \\
\hline
\end{tabular}

${ }^{\mathrm{a}} \mathrm{AVD}$ : average view duration.

Table 3. Sharing services.

\begin{tabular}{lll}
\hline Sharing services & Jan 2014-Dec 2016, n=175 (times shared), n (\%) & Jan 2017-Dec 2019, n=1011 (times shared), n (\%) \\
\hline WhatsApp & $111(66.4)$ & $677(67.0)$ \\
Email & $23(13.1)$ & $39(3.8)$ \\
Facebook & $6(3.4)$ & $29(2.8)$ \\
Text message & $6(3.4)$ & $60(5.9)$ \\
Other & $29(16.6)$ & $206(20.4)$ \\
\hline
\end{tabular}

\section{Discussion}

\section{Principal Findings}

As the power of social media increases, YouTube has become an indispensable e-mental health platform. In this study, we aimed to investigate the means that the Chinese-speaking public search for and share dementia education videos, and evaluate the usage of various social media platforms over time. Although prior studies have aimed to analyze the potential of YouTube and WhatsApp as means for disseminating dementia education, this is the first study to analyze data over a 6-year period-comparing the first and second 3 years — and provide statistical analysis of not only the trends in devices used for viewing but also the dynamic shift in traffic sources and usage of sharing services [11-16]. Overall, the latter 3 years had increased performance than the first 3 years including longer total watch time (59,262 vs 210,126 minutes), increased number of views (9387 vs 28,303 views), and longer average view duration (6.3 vs 7.4 minutes). Previous studies have reported a 6-minute median engagement time across online educational videos of varying lengths [17]. The increase in average view duration in the second 3-year period from 6.3 to 7.4 minutes demonstrates that the dementia educational videos were able to not only capture but also retain viewers' attention.

The chi-square analysis showed significant difference in our following analyses. Compared to computer use, average view duration on mobile devices remained and increased far more than on computers between the first and second 3-year intervals (6.9-8.1 minutes). This demonstrates the increasing popularity of using a mobile device over a computer to watch the educational videos. Electronic health (eHealth) communication efforts should therefore ensure mobile device compatibility to maximize audience.

Analysis of traffic sources revealed that YouTube's suggested videos have consistently been the main source of traffic in the last 6 years. However, the analysis of external traffic sources revealed notable findings. Comparing the first and second 3-year periods, Google search traffic source remained relatively the same $(1.5 \%, 138 / 9387$ to $1.1 \%, 302 / 28,303$ of views), Facebook generated traffic source decreased $(0.3 \%, 30 / 9387$ to $0.2 \%$, $54 / 28,303$ of views), and WhatsApp traffic source increased and even surpassed that of Google search $(0.6 \%, 59 / 9387$ to $3.3 \%, 929 / 28,303$ of views). This demonstrates the significant rise in popularity of WhatsApp in the latter 3 years and suggests that WhatsApp could be the future platform for dementia education and eHealth communication alike.

Our study also demonstrates that WhatsApp has evolved into a leading means of sharing dementia knowledge among the Chinese American community. Between the first and second 3-year periods, WhatsApp and text message have both experienced increase in usage as sharing services, while Facebook and email have both dramatically decreased. Previous studies have suggested that WhatsApp is used more for its sharing capability than for its viewing function [16]. Our study confirms this finding and reinforces the claim with 6 years of 
longitudinal data. Not only has WhatsApp become the preferred means of sharing dementia knowledge, but it has also exceeded Google search and has become the top external source of traffic.

\section{Limitations}

This study has several limitations. First is the lack of demographic information about the viewers. Because all video content was in Chinese and limited to US residents, it was assumed that our study population was largely Chinese American. The ability to collect demographic information would enable analysis of the impact of ethnicity and socioeconomic status on social media use. Second, because there was no measure of viewers' knowledge of dementia prior to and after watching the videos, we were unable to evaluate the effectiveness of the videos as an educational tool. Third, this study is a retrospective longitudinal analysis of data extrapolated from YouTube Analytics. As such, analysis was constrained to the variables and data collected by YouTube Analytics. In the future, prospective studies should focus on the role of WhatsApp in the dissemination of eHealth content. Last, as each video was 25-minutes long, there was a relatively short average viewing duration of 6.3 to 7.4 minutes. A shorter average viewing duration would preclude effective delivery of important information. Shortening the video length and applying more engaging, interactive content could inherently improve viewer attention, viewing duration, and, ultimately, retention of educational content. Efforts to decrease stigma and negative perceptions toward dementia are essential to provide and coordinate care for the Chinese American population. Future directions include the continued study of the long-term impact that social media has in health communication to populations of interest.

\section{Conclusion}

YouTube has proven to be a valuable tool to deliver culturally sensitive dementia education to Chinese Americans, thereby reducing the disparity of dementia knowledge in linguistically and culturally isolated populations. WhatsApp continues to be a preferred method of sharing dementia education and has become a top external traffic source to dementia educational videos. Use of these findings and continued study of how social media can be used in health communication are imperative to work in disseminating knowledge, reducing stigma, and promoting early detection and treatment in the older Chinese American population.

\section{Conflicts of Interest}

None declared.

\section{References}

1. Moorhead SA, Hazlett DE, Harrison L, Carroll JK, Irwin A, Hoving C. A new dimension of health care: systematic review of the uses, benefits, and limitations of social media for health communication. J Med Internet Res 2013 Apr 23;15(4):e85 [FREE Full text] [doi: 10.2196/jmir.1933] [Medline: 23615206]

2. Kwok TM, Singla AA, Phang K, Lau AY. YouTube as a source of patient information for varicose vein treatment options. J Vasc Surg Venous Lymphat Disord 2017 Mar;5(2):238-243. [doi: 10.1016/j.jvsv.2016.10.078] [Medline: 28214492]

3. Woo BKP, Harwood DG, Melrose RJ, Mandelkern MA, Campa OM, Walston A, et al. Executive deficits and regional brain metabolism in Alzheimer's disease. Int J Geriatr Psychiatry 2010 Nov;25(11):1150-1158. [doi: 10.1002/gps.2452] [Medline: 20069587]

4. Small GW. Diagnosis and treatment of Alzheimer disease and related disorders. JAMA 1997 Oct 22;278(16):1363. [doi: 10.1001/jama.1997.03550160083043]

5. Woo BK, Mehta P. Examining the differences in the stigma of dementia and diabetes among Chinese Americans. Geriatr Gerontol Int 2017 May;17(5):760-764. [doi: 10.1111/ggi.12782] [Medline: 27137751]

6. Zheng X, Woo BKP. Association between recognizing dementia as a mental illness and dementia knowledge among elderly Chinese Americans. World J Psychiatry 2016 Jun 22;6(2):233-238 [FREE Full text] [doi: 10.5498/wjp.v6.i2.233] [Medline: 27354966]

7. Woo BK. Family history and its relationship with dementia stigma beliefs among Chinese Americans. Geriatr Gerontol Int 2017 Jan;17(1):122-125. [doi: 10.1111/ggi.12686] [Medline: 26694867]

8. Woo BK. Dementia health promotion for Chinese Americans. Cureus 2017 Jun 29;9(6):e1411 [FREE Full text] [doi: 10.7759/cureus.1411] [Medline: 28856076]

9. Woo BKP. Using a Chinese radio station to disseminate dementia knowledge to Chinese Americans. J Am Geriatr Soc 2012 Nov;60(11):2175-2176. [doi: 10.1111/j.1532-5415.2012.04230.x] [Medline: 23148425]

10. Zheng X, Chung JOP, Woo BKP. Exploring the impact of a culturally tailored short film in modifying dementia stigma among Chinese Americans: a pilot study. Acad Psychiatry 2016 Apr;40(2):372-374. [doi: 10.1007/s40596-015-0397-7] [Medline: 26307362]

11. Zheng X, Woo BK. E-mental health in ethnic minority: a comparison of youtube and talk-based educational workshops in dementia. Asian J Psychiatr 2017 Feb;25:246-248. [doi: 10.1016/j.ajp.2016.12.002] [Medline: 28262161]

12. Lam NHT, Tsiang JT, Woo BKP. Exploring the role of YouTube in disseminating psychoeducation. Acad Psychiatry 2017 Dec;41(6):819-822. [doi: 10.1007/s40596-017-0835-9] [Medline: 29022242]

13. Lam NHT, Woo BKP. YouTube as a new medium for dementia education among Chinese Americans. Community Ment Health J 2020 Apr;56(3):435-439. [doi: 10.1007/s10597-019-00493-7] [Medline: 31641910] 
14. Woo BK, Kung E. A YouTube video intervention as mHealth to promote first-episode psychosis education to Chinese. Asian J Psychiatr 2018 Mar;33:38-39. [doi: 10.1016/j.ajp.2018.02.021] [Medline: 29518750]

15. Lam NH, Woo BK. Exploring the role of YouTube in delivering dementia education to older Chinese. Asian J Psychiatr 2018 Jan;31:25-26. [doi: 10.1016/j.ajp.2017.12.022] [Medline: 29324268]

16. Nguyen B, Woo BKP. Sharing is caring: WhatsApp as a method of disseminating dementia knowledge to elderly Chinese Americans. Int. Psychogeriatr 2019 Jun 21;32(2):281-282. [doi: 10.1017/s1041610219000656]

17. Guo P, Kim J, Rubin R. How video production affects student engagement: an empirical study of MOOC videos. 2014 Mar 04 Presented at: First ACM Conference on Learning @ Scale; March 4, 2014; Atlanta p. 41-50. [doi: $\underline{10.1145 / 2556325.2566239]}$

\title{
Abbreviations \\ AVD: average view duration \\ eHealth: electronic health
}

\author{
Edited by J Wang; submitted 09.02.20; peer-reviewed by T Dunnsiri, X Zheng; comments to author 20.02.20; revised version received \\ 21.02.20; accepted 26.02.20; published 13.04.20 \\ Please cite as: \\ Shu $S$, Woo BKP \\ The Roles of YouTube and WhatsApp in Dementia Education for the Older Chinese American Population: Longitudinal Analysis \\ JMIR Aging 2020;3(1):e18179 \\ URL: http://aging.jmir.org/2020/1/e18179/ \\ doi: $\underline{10.2196 / 18179}$ \\ PMID: 32281940
}

(CSara Shu, Benjamin K P Woo. Originally published in JMIR Aging (http://aging.jmir.org), 13.04.2020. This is an open-access article distributed under the terms of the Creative Commons Attribution License (https://creativecommons.org/licenses/by/4.0/), which permits unrestricted use, distribution, and reproduction in any medium, provided the original work, first published in JMIR Aging, is properly cited. The complete bibliographic information, a link to the original publication on http://aging.jmir.org, as well as this copyright and license information must be included. 